Article

\title{
An Integrated Approach for Monitoring and Information Management of the Guanling Landslide (China)
}

\author{
Wei Hou ${ }^{1}$, Xuejun Lu ${ }^{2, *}$, Pengda Wu ${ }^{1}$, An Xue ${ }^{3}$ and Liuke Li $^{2}$ \\ 1 Chinese Academy of Surveying and Mapping, Beijing 100830, China; houwei@casm.ac.cn (W.H.); \\ wupd@casm.ac.cn (P.W.) \\ 2 Institute of Geographic Sciences and Natural Resources Research, Chinese Academy of Sciences, \\ Datun Road 11, Beijing 100101, China; lilk@igsnrr.ac.cn \\ 3 College of Environment Sciences and Engineering, Peking University, Yiheyuan Road 5, Beijing 100871, \\ China; xuean@iee.pku.edu.cn \\ * Correspondence: luxuejun@igsnrr.ac.cn
}

Academic Editors: Jason K. Levy, Christoph Aubrecht and Wolfgang Kainz

Received: 16 November 2016; Accepted: 8 March 2017; Published: 12 March 2017

\begin{abstract}
Landslide triggered by earthquake or rainstorm often results in serious property damage and human casualties. It is, therefore, necessary to establish an emergency management system to facilitate the processes of damage assessment and decision-making. This paper has presented an integrated approach for mapping and analyzing spatial features of a landslide from remote sensing images and Digital Elevation Models (DEMs). Several image interpretation tools have been provided for analyzing the spatial distribution and characteristics of the landslide on different dimensions: (1D) terrain variation analysis along the mass movement direction and (3D) morphological analysis. In addition, the results of image interpretation can be further discussed and adjusted on an online cooperating platform, which was built to improve the coordination of all players involved in different phases of emergency management, e.g., hazard experts, emergency managers, and first response organizations. A mobile-based application has also been developed to enhance the data exchange and on-site investigation. Our pilot study of Guanling landslide shows that the presented approach has the potential to facilitate the phases of landslide monitoring and information management, e.g., hazard assessment, emergency preparedness, planning mitigation, and response.
\end{abstract}

Keywords: landslide monitoring; hazard emergency management; image interpretation; online cooperating platform

\section{Introduction}

Landslides can cause significant property loss and human casualties. China has been frequently affected from such natural hazards, especially in Southwest China [1,2]. How to monitor and quickly respond to unexpected geological disasters has a strong practical significance. During a sudden landslide event, it is important for decision-makers, experts, and other official managers to access the information about the topography of the mass flow, the flow volume, the potential affected area, and so on.

Remote sensing as a promising technology has a wide range of applications in landslide studies [3-5]. The landslide-related studies can be concluded in three stages: (a) detection and identification; (b) monitoring; and (c) spatial analysis and hazard prediction [4,6,7]. The use of remote sensing data (airborne, satellite, or ground-based) varies according to the three main stages above. For monitoring landslide movements, the quantitative volumetric analysis was often adopted by using a 
series of DEMs derived from the available topographical maps or airborne images [8]. As concluded by Kääb [9], analytical and digital photogrammetry techniques are highly suitable for monitoring geometric changes in high mountains and obtaining surface information, such as terrain displacement. Especially by using the airborne laser scanning technology, it is convenient for rapidly collecting high densities of precise and high-resolution 3D point coordinates, which can be used for 3D geometrical modeling and analyzing the surface topography of a landslide [10,11].

Additionally, a large volume of imagery data can conveniently be acquired, stored, and analyzed in digital form using the Geographical Information System (GIS) [12-15]. GIS-based analysis techniques for landslide monitoring have been widely applied since the advancement of GIS technology [1,16-18]. The combination of remote sensing and GIS has emerged as an effective approach to detect, identify, map, survey, and monitor existing hazards $[11,12,19]$. It can be viewed as a knowledge mining process, in which meaningful features can be used to characterize landslides for damage assessment and decision-making [20], yielding vital knowledge for damage mitigation and response efforts. However, most approaches for landslide monitoring and hazard management are insufficient to fulfill the needs for rapid responds of emergency events. A collaborative, multimodal, and interactive hazard monitoring system may cover such a gap [21]. Many researchers have shown the applicability of web-based mapping in emergency management. Lichter et al. [22] illustrated how web-based mapping can be used for both generating and conveying outcomes in post-disaster management to a broader audience. Hagemeier-Klose and Wagner [23] evaluate the use of web mapping method in visualizing results and communicating flood risk to policy makers, planners, and the informed public.

In this research, an integrated approach combining RS image acquisition, processing, and GIS-based hazard assessment are integrated in a web-based mapping environment, allowing the integration of both historical and real-time data with geographic and cartographic information concerning the region being monitored. The objective is to fulfill the requirement of real-time emergency response and contribute to the enhancement of methods and tools for geological hazards management. The final product will be a hazard monitoring and information management system, comprising a database, hazard assessment models, and an online cooperating platform.

\section{Methodical Basis and System Design}

To accelerate the hazard assessment and landslide information management, an emergency response system is designed. Figure 1 shows the framework and components of the system. The system is built on different types of network infrastructures (Figure 1). Initial data can be collected by satellites or other facilities (e.g., Personal Digital Assistant (PDA) and Unmanned Aerial Vehicles (UAVs)). Processed results are exchanged and shared through a Local Area Network (LAN) or the Internet. A geological hazard monitoring database is designed by using ADO.NET technology, Oracle $11 \mathrm{~g}$ database and ArcSDE, which are used for storage and access management of spatial data, such as aerial and satellite images, geo-referenced thematic data, and real-time monitoring results. A decision-making system is used to employ emergency hazard analysis and provides decision support for multi-users based on analysis result. Image analysis and processing model is developed in ArcGIS Server 10.2. Changes on surface elevation of a landslide is usually used for analyzing the movement and the volume of the material involved [24,25]. It can be simply calculated by subtracting the DEM of pre-landslide along the longitudinal profile from the DEM of post-landslide. If the differences of a certain section along the profile are negative, the area around the section possibly belongs to the zone of depletion (negative terrain); if positive, it possibly belongs to the zone of accumulation (positive terrain). A landslide motion mechanism can be further investigated by analyzing the length, slope, and curvature of every section of the profile. Based on the morphological analysis, various zones and the volume of the landslide are determined, and the preliminary affecting range is estimated for hazard evaluation. 


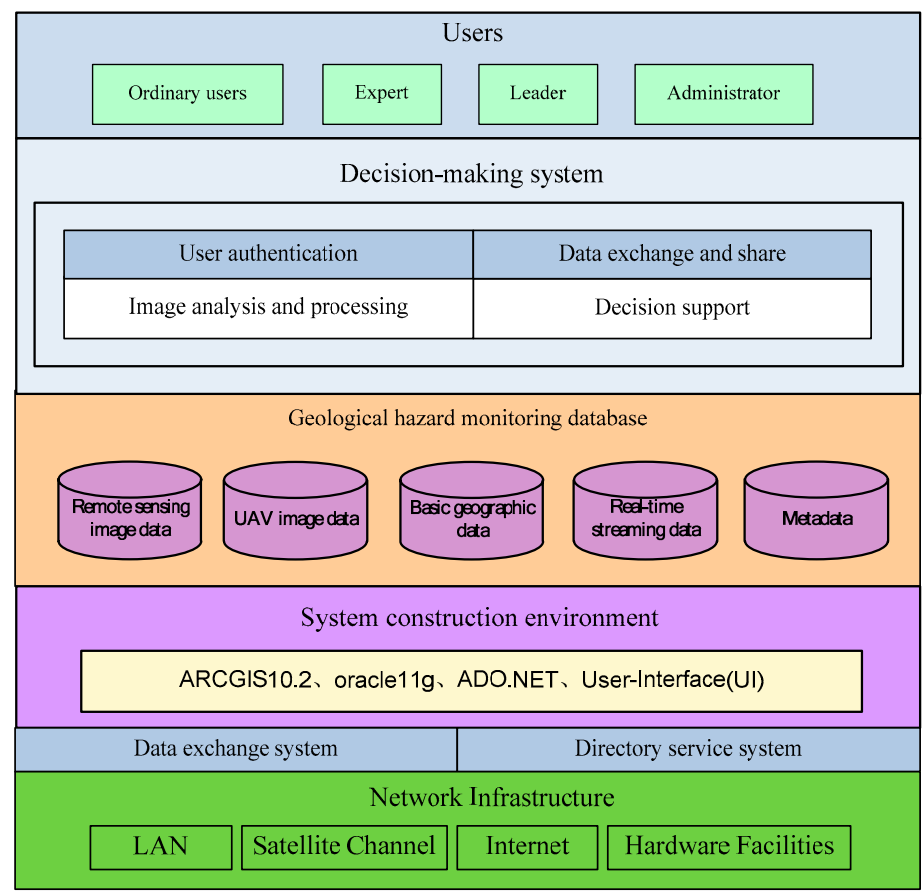

Figure 1. System design and components.

Existing landslide monitoring and management system mostly has the functions of data collection, disaster information production and distribution $[14,26]$. Real-time data collection and processing is the key to emergency management. Besides the general methods for data collection in hazard event (e.g., remote sensing and UAVs), we have developed a smartphone application that is used by people engaged in the hazard event for real-time ground data collection (photos, short video, etc.). Additionally, we have supplied an online cooperating emergency platform to achieve a real-time information exchange and communications among all decision-makers and experts in distinct locations for interactive cooperation. It supplies the functions of video conference and collaborative feature editing, which make the landslide analysis and hazard evaluation easier among different departments and multi-users. All users can access the database and decision-making system through a web browser on a computer with Microsoft Windows or a smartphone using an Android application developed with JDK (Java Development Kit) 1.7 (Figure 2). With the support of this online cooperating platform, we can distribute the landslide information in a short interval once the data is collected or processed. In this case, we have not only integrated different data sources (satellite/UAV images, DEMs, on-site photos, etc.), but also different applications (desktop, web-based, mobile app) for data collecting, processing, and sharing information, which can potentially enhance the process of hazard analysis and risk information management.

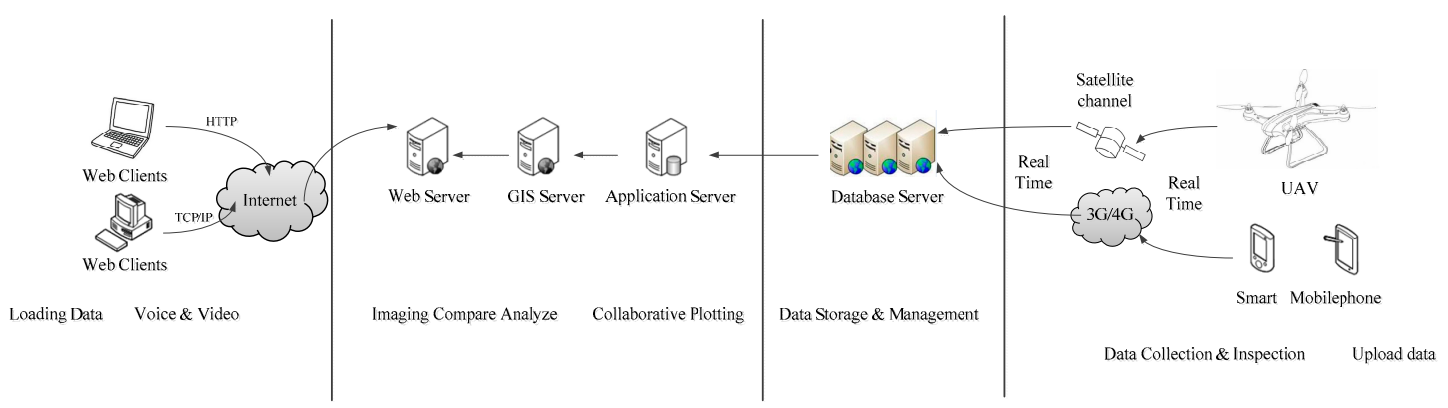

Figure 2. System configuration of online cooperating platform. 


\section{Case Study}

\subsection{Study Area}

On 28 June 2010, a catastrophic landslide occurred in Guanling County, Guizhou Province of China (Figure 3). During this event, the local rainfall in $24 \mathrm{~h}$ reached $310 \mathrm{~mm}$, the highest in the last 60 years. The climate and extreme weather became the trigger of this hazard, which caused severe human casualties and property losses. This landslide was used as a pilot study to show the application of the landslide information and monitoring system.

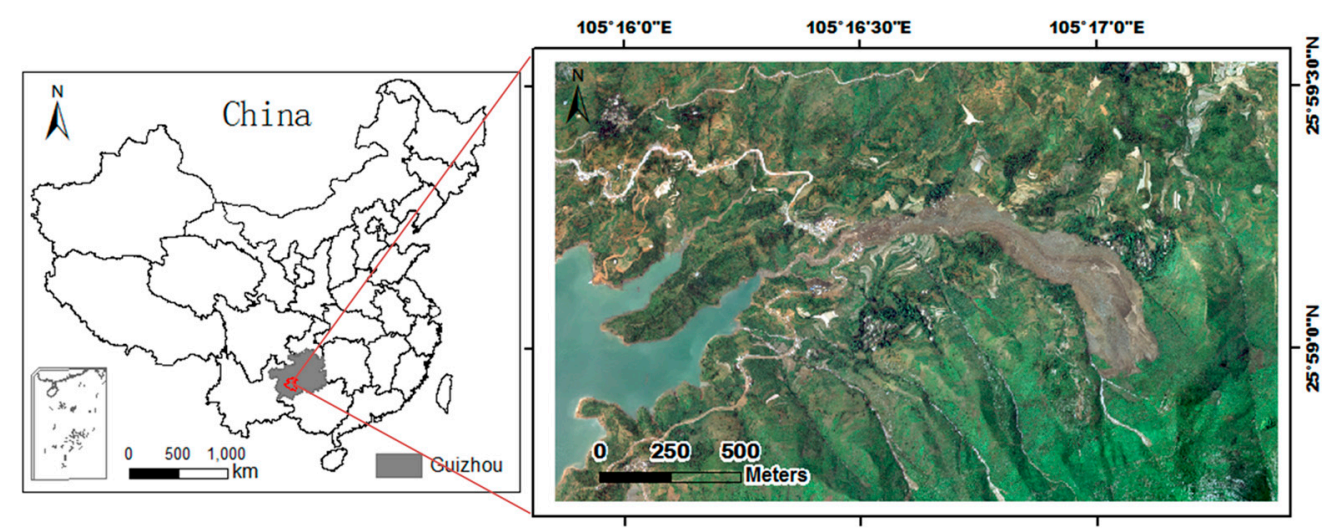

Figure 3. Location and aerial image of Guanling Landslide.

\subsection{Data Sources}

The data used in the emergency hazard information system can be classified into two categories: pre-landslide and post-landslide. The images in this region before landslide were collected from QuickBird satellite in February 2010 and preprocessed (e.g., geometric correction and projection transformation) in the format ready for further interpretation. The Digital Elevation Model (DEM) before landslide was produced from the topographical map in 2009, which was collected from the local bureau of surveying and mapping. In addition, Triangular Irregular Network (TIN) was generated based on the DEM.

On 30 June, a quad-rotor UAV flight campaign was carried out covering the whole sliding area of the Guanling landslide (as shown in Figure 4). More than 200 optical photos and POS (position and orientation system) data were collected from three flights. POS data contains the aerial photo number, space position X, Y, H coordinates, small aircraft attitude rolling, pitching, flip, and other information. To serve the geological disaster analysis, two processing procedures were carried out: an ortho-mosiac was generated, and a DEM model was established using point cloud data. First, each image was rectified onto the center point coordinates recorded in POS data, photo size, and ground control points and flip angle. Then, all rectified photographs were merged to a uniform ortho-mosaic with a spatial resolution of $0.1 \mathrm{~m}$. All correction was carried out by using PhotoScan software, which is an advanced image-based 3D modeling solution [27,28]. DEM was also created by using PhotoScan software, which can extract the point cloud data from the coordinate information of POS data, and reconstruct the digital elevation model. The DEM after landslide was produced in a $2 \mathrm{~m}$ resolution and it was converted to vector format (TIN) for further analysis. A detailed description of each input layer is shown in Table 1. 


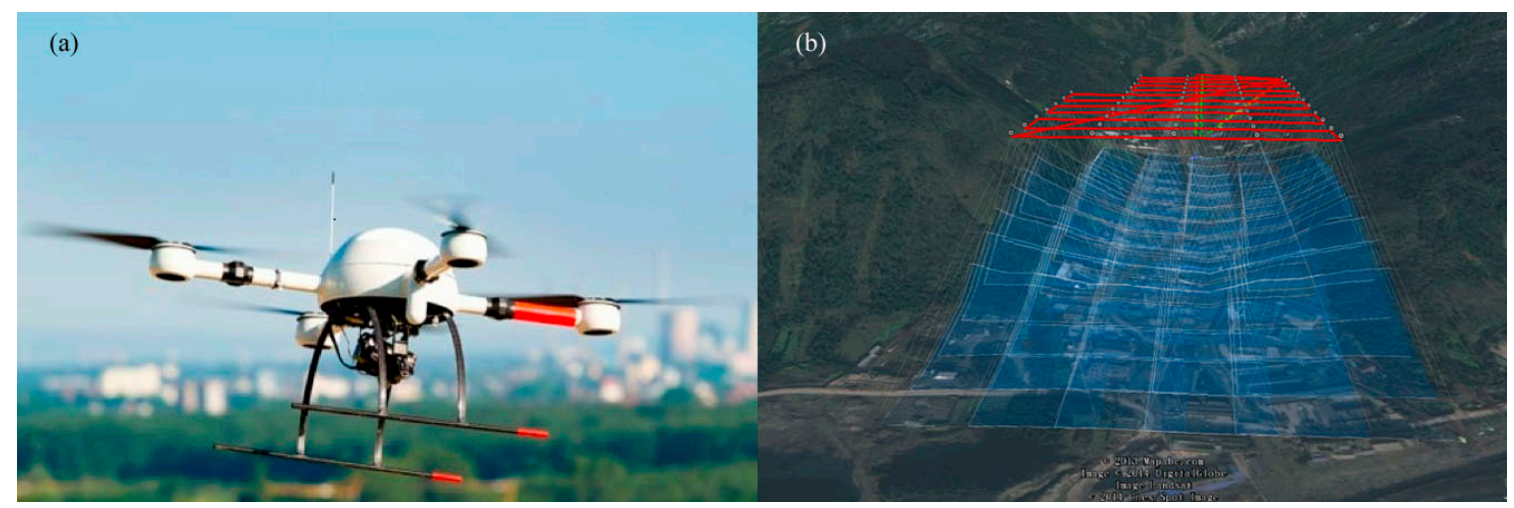

Figure 4. An unmanned aerial vehicle (UAV) and its path in one flight.

Table 1. Data collection and description of pre-landslide and post-landslide.

\begin{tabular}{|c|c|c|c|}
\hline Layer & Format & Acquired Date & Description \\
\hline \multicolumn{4}{|r|}{ Pre-landslide } \\
\hline QuickBird image & Raster & 06.02 .2010 & Spatial resolution: multi-spectral band $2.4 \mathrm{~m}$ and panchromatic band $0.61 \mathrm{~m}$ \\
\hline Topographical map & Raster & 2009 & The scale of $1: 50,000$ \\
\hline DEM & Raster & 2009 & Extracted from topographical data in $5 \mathrm{~m}$ resolution \\
\hline Slope map & Raster & 2009 & Extracted from DEM before landslide \\
\hline TIN & Vector & 2009 & Generated based on DEM \\
\hline Land use map & Vector & 2010 & The land use map was classified by QuickBird image and topographical map \\
\hline Administrative border & Vector & 2010 & Administrative division of the study area \\
\hline \multicolumn{4}{|r|}{ Post-landslide } \\
\hline Aerial image & Raster & 30.06 .2010 & True color in $0.1 \mathrm{~m}$ resolution \\
\hline Landslide extent & Vector & 30.06 .2010 & Delineated based on the aerial image \\
\hline DEM & Raster & 30.06 .2010 & Derived from POS data in $2 \mathrm{~m}$ resolution \\
\hline Slope map & Raster & 30.06 .2010 & Extracted from DEM after landslide \\
\hline TIN & Vector & 30.06 .2010 & Generated based on DEM \\
\hline
\end{tabular}

\subsection{Image Interpretation}

We supplied different spatial analysis tools for image interpretation. The DEM variation along the mass movement direction could be used for representing the sliding process. A one-dimensional tool for a cross-sectional profile graph was used to quantitatively evaluate the intensity of the rapid surface displacement. Figure 5 shows displacement vectors measured along the cracks by using this one-dimensional tool. The positive and negative terrain changes caused by the landslide can be observed from the intersection of two elevation curves. It indicated that the most likely sliding mechanism is stepped-like planar failure during the Guanling landslide. Potentially, the length of the landslide was estimated roughly 1700 m, and the curves in Figure 5 can be divided into three sections:

- The section from Point A to Point B belonged to the negative terrain. Its elevation ranged from $1085 \mathrm{~m}$ to $1199 \mathrm{~m}$, and the elevation difference was $114 \mathrm{~m}$. The length of the AB section was about $200 \mathrm{~m}$ in the crack direction. Before the landslide, the degree of the slope in this section ranged from 26 to 37 degrees, while the slope changed to a range between 39 and 53 degrees after the landslide.

- The section from Point B to Point $C$ belonged to the positive terrain. Its elevation ranged from $755 \mathrm{~m}$ to $1085 \mathrm{~m}$, and the elevation difference was $330 \mathrm{~m}$. The length of the BC section was about $1150 \mathrm{~m}$ in the crack direction. Before the landslide, the degree of the slope in this section ranged from 9 to 16 degrees, while the slope changed to a range between 0 and 15 degrees after the landslide.

- The section from Point $C$ to Point $D$ belonged to the negative terrain. Its elevation ranged from $735 \mathrm{~m}$ to $755 \mathrm{~m}$. The length of the CD section in the crack direction was about $350 \mathrm{~m}$. After the landslide, this section changed to a nearly flat area. 


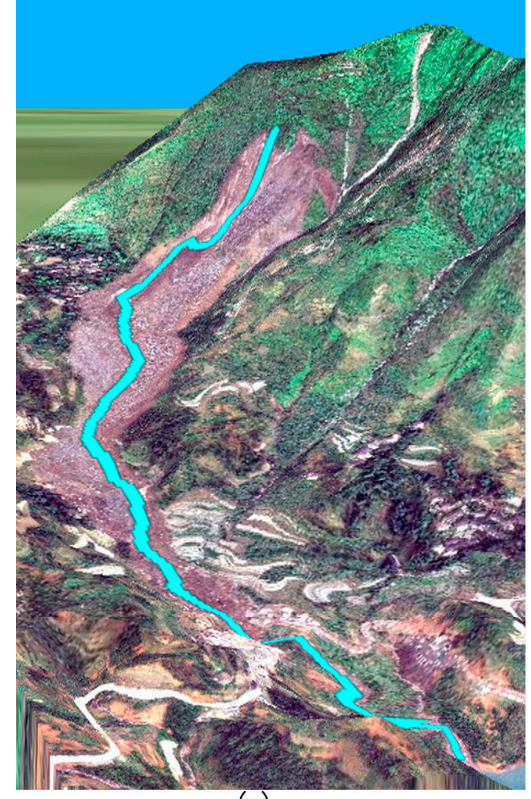

(a)

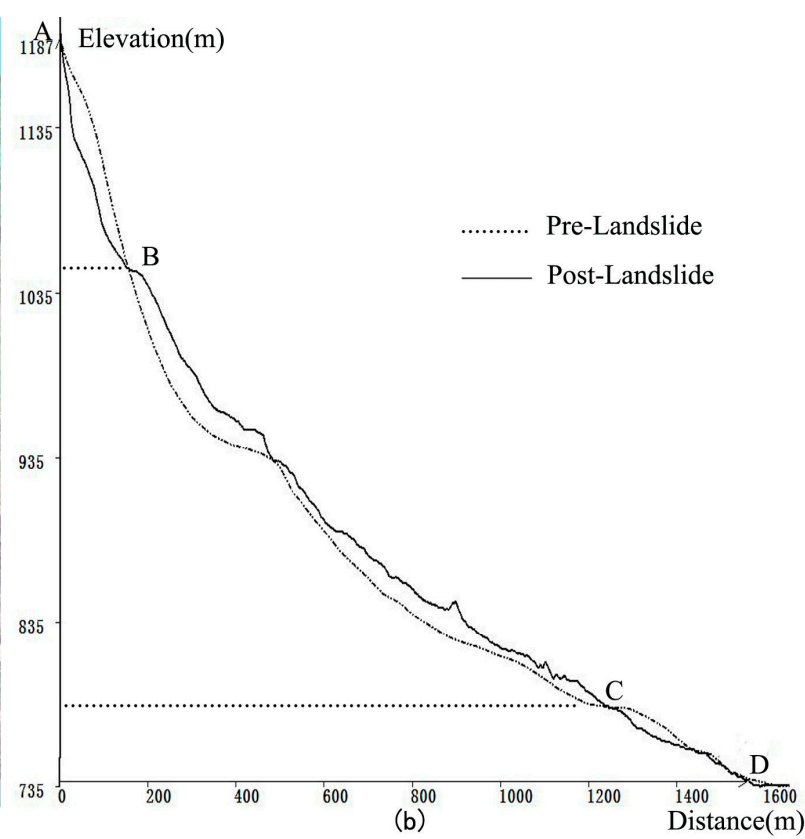

(b)

Figure 5. Cross section of the surface instability in the potential movement direction showing potential unstable masses: (a) drawing the topographical profile line based on crack orientation; (b) elevation variation before and after the landslide event.

To further confirm the configuration of the landslide body, a fine interpretation tool for the landslide in the three-dimensional environment was developed. This tool was implemented in a multi-window linked environment. A high-precision 3D grid was created based on the DEM and overlaid with the aerial photos. Images of pre- and post-landslide can be simultaneously compared that would be helpful in the process of delineating the instability zones. As shown in Figure 6, the landslide body can be divided as the main scarp, the zone of depletion, and the zone of accumulation by visual interpretation. The main scarp, which showed a very steep terrain, belonged to the negative terrain, and its elevation decreased averagely $25 \mathrm{~m}$. The zone of depletion belonged to the positive terrain, and the average slope changed from 12.5 to 7.5 degrees after the landslide. Within the zone of accumulation, the terrain became generally flat and the elevation increased averagely $10 \mathrm{~m}$. Based on the different zones of the sliding surface, the volume of potential instability was calculated in a GIS environment by subtracting from the TINs created from the constructed surface. In this case, the total surface area of the landslide was estimated $5.25 \times 10^{5} \mathrm{~m}^{2}$ and the total volume of the slide body was $4.25 \times 10^{6} \mathrm{~m}^{3}$.

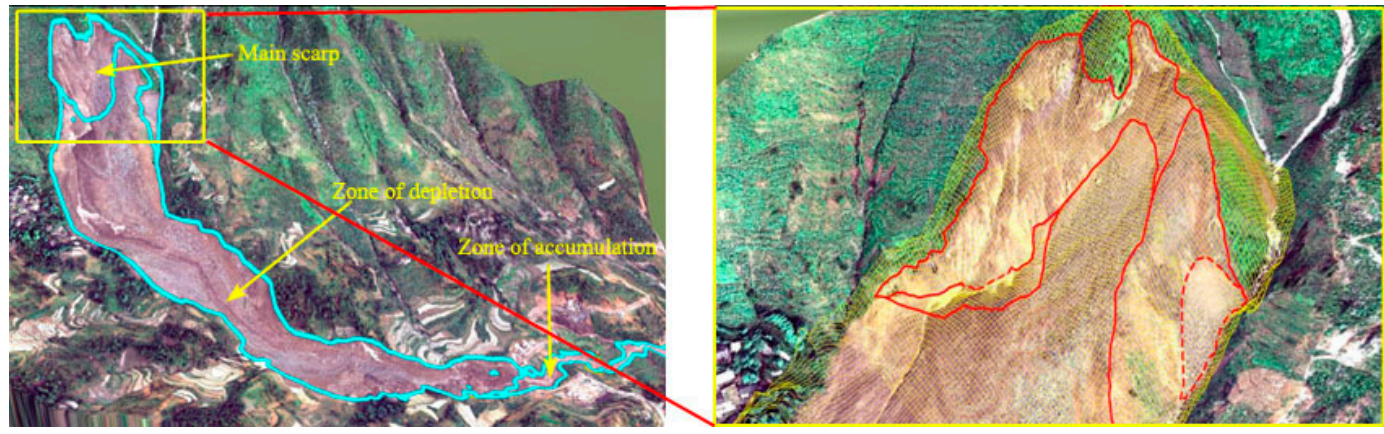

Figure 6. Three main zones of instability of observed landslide: main scarp, zone of depletion, and zone of accumulation. 
The area affected or damaged by landslides is important information for planning mitigation and emergency respond. The affected area map can be created by overlaying the extent of the landslide with different thematic layers, e.g., traffic road and settlements. An example of the affected settlement by this landslide was shown in Figure 7 . Over $75 \%$ of the affected area was farmland, covering an area of about 80 hectares. There were two villages located in this region where 16 houses in Dazhai Village and 17 houses in Yongwo Village were buried by the mass debris in Guanling Landslide.

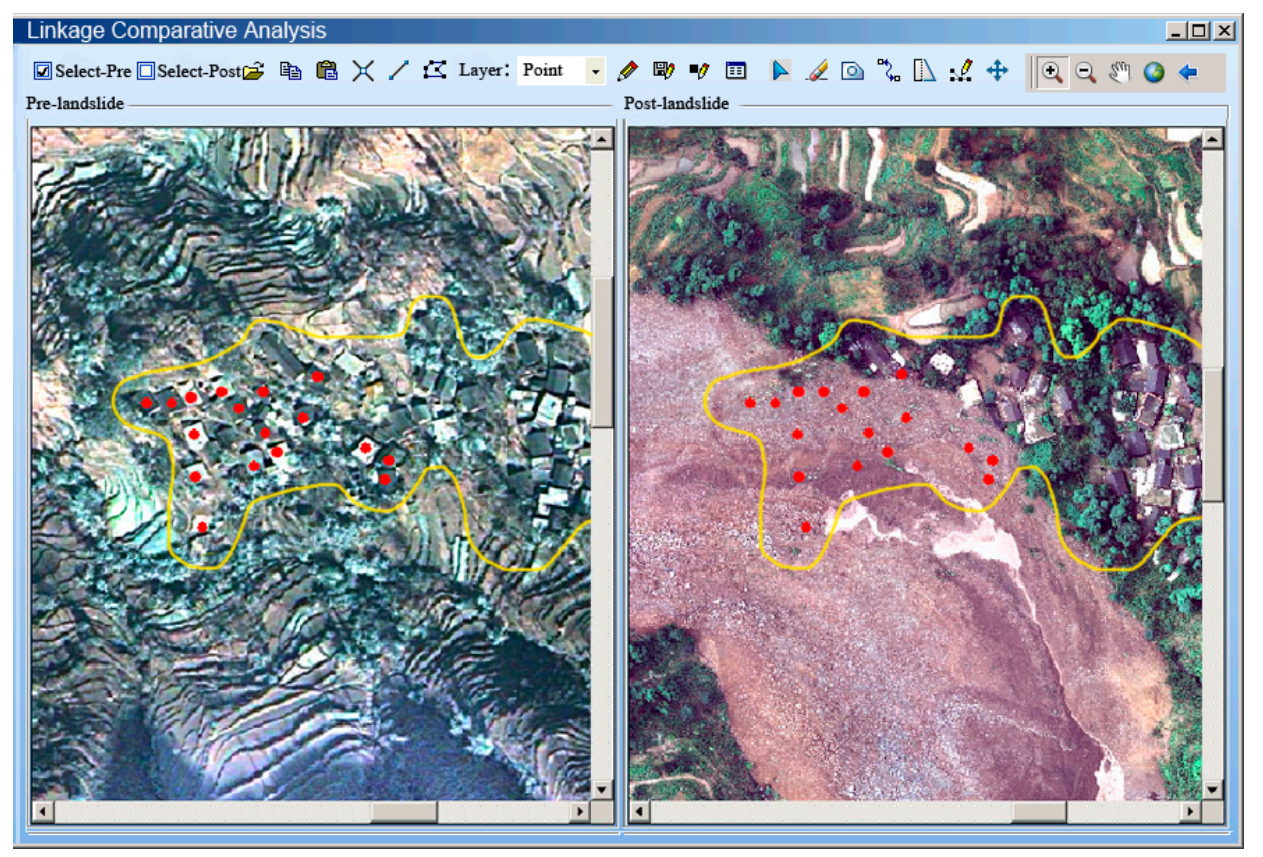

Figure 7. Area affected by landslide (red points stand for the ruined houses in Yongwo Village).

\subsection{Implementation of Emergency Management Platform}

The results of image interpretation and related data can be processed and shared through an online cooperating emergency platform. It provides a video conference system and additional editing tools based on web-GIS functions used for hazard analysis (see Figure 8). A further image interpretation and hazard assessment can be achieved through online discussion of the experts. It had basic tools for drawing and editing on the hazard map. In addition, a mobile application was developed for on-site data collection and verification. On-site photos and videos can be collected and sent back to the data center through the application. The developed online platform can be used to improve the coordination of all players involved (e.g., hazard experts, emergency managers, and first response organizations) in all phases of emergency management. 


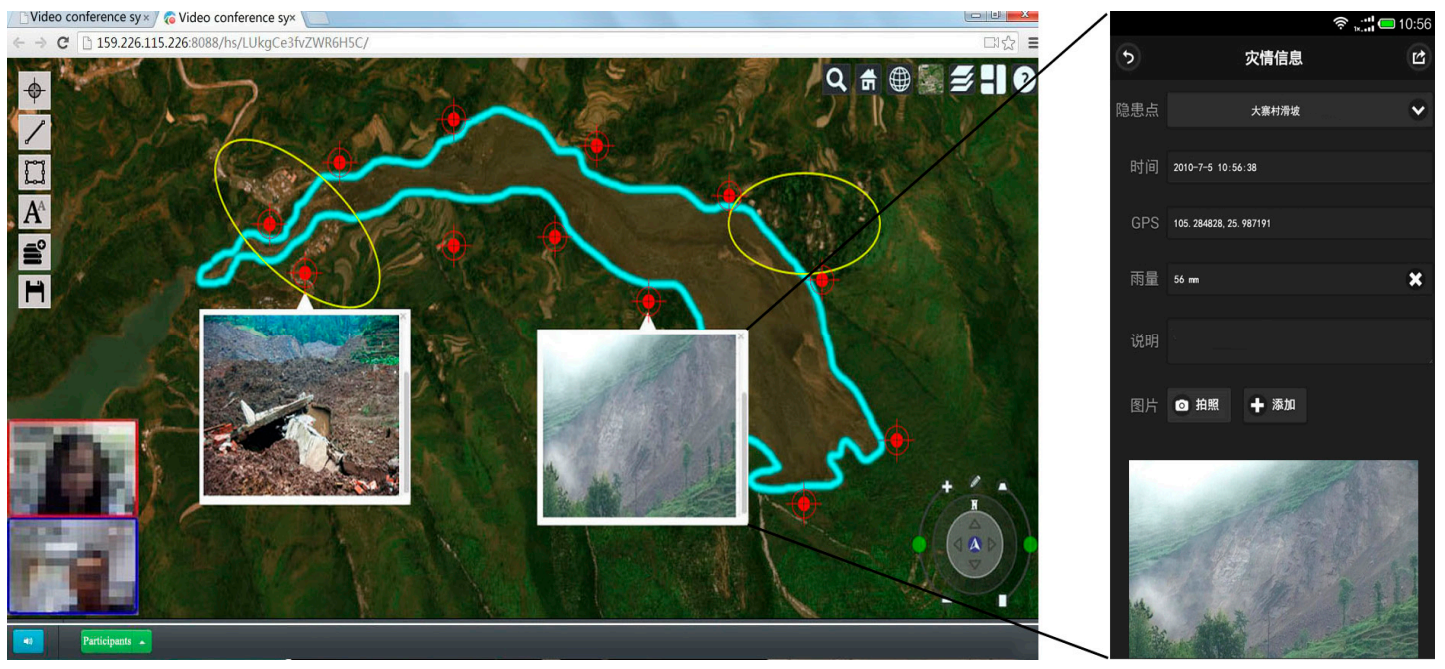

Figure 8. Collaborative analysis of landslide in Web environment.

\section{Discussion}

\subsection{Data Requirement}

Photogrammetry has the potential to determine surface information, whereas it has no access to depth information that has to be obtained from geophysical approaches [4]. The accuracy of hazard assessment relies on the quality of remote sensing imagery and DEMs. For instance, the accuracy of the volumetric computations depends on the temporal and spatial resolution of DEMs. The post-landslide data can be collected by UAV within a short interval after the event. It is often the case that the DEM before the landslide is not in a reliable condition. In our case study, the DEM before landslide was produced from the topographical map at the scale of 1:50,000. In order to do a joint analysis with the post-landslide DEM derived from LIDAR, the resolution of pre-landslide DEM has been resampled in $2 \mathrm{~m}$. This would result in miscalculations in hazard analysis and the accuracy of boundaries will be potentially misleading. In order to reduce the plane error between the DEMs before and after landslide, a two-dimensional maximum correlation matching method was used by calculating the volume of landslide body based on the principle of material balance by summing up the morphological changes of the landslide [29]. Generally, the resolution and quality of the input data determines the accuracy of the produced hazard maps [30]. The applicability of the supplied tools for hazard analysis is related to the level and scale of landslide mapping [31,32]. Due to the limitation of input data, it could be helpful for hazard analysis by combining both the DEM and high resolution aerial photos in a three-dimensional environment. However, onsite investigation would be still necessary to detect debris boundaries, especially for site specific decisions based on hazard maps.

\subsection{Hazard Assessment}

Under the support of RS/GIS technology, the hazard assessment was implemented by the guidance of experts' experience by using the supplied tools. This semi-automated image analysis approach was relatively efficient and it resulted in two maps, i.e., landslide hazard map and affected area map. The hazard map showed the landslide location and the detailed body information of the landslide. The GIS modeling approach have been widely adopted and proved to be useful in hazard assessment $[5,13,17,33]$. It is timesaving and cost-efficient, which fits to the aim of our designed emergency management. The visualized and quantitative results of GIS modeling could give a preliminary understanding of the landslide in this event. To verify and validate the results of hazard analysis other thematic layers would be useful as assistant data, such as land cover and slope. The final version of this map was produced in consultation with all involved experts and on-site investigation. 
The affected area map provided information on the areal extent of the possible damaged settlement or transportation. Such a map could be used in the process of damage mitigation and the land-use planning of reconstruction. In our case study, this map was prepared using the high resolution aerial photo. However, damage intensity to buildings and infrastructures can be varied according to the speed of mass flow. In this case, the on-site photos can be helpful for estimating the damage loss. The advantages of both qualitative and quantitative methods could be adopted in the hazard assessment based on the site-specific experience of experts [34].

\subsection{Online Cooperating Platform}

The web-based platform facilitated landslide management and emergency operation based on output products from the hazard assessment modules. This developed platform was especially useful for emergency management professionals and first response organizations after the landslide event. Experts and other official managers can access the system through the internet with a computer or mobile phone. It extends desktop GIS capabilities to an internet environment and thus encourages the development of handy applications that are accessible, dynamic, and interactive $[22,35]$. In this study, the web-based platform was applied for further hazard investigation, emergency preparedness, planning mitigation, and response by improving the coordination of actions among all players involved in landslide response. In a next step, more spatial analysis tools based on web-GIS functions should be added to strengthen its ability for online mapping.

\section{Conclusions}

Understanding and modeling of landslides requires access to spatially referenced data from a wide variety of sources, including remote sensing at different resolutions and reliability, often multi-temporal, as well as the analyses of such data in a multi-dimensional space $[4,28,29]$. Thus, the proposed landslide information and monitoring system combines the remote sensing and GIS spatial analysis techniques within an online cooperating platform. Additionally, the web-based platform supplies editing tools by which the degree of hazard can be further mapped directly online by authorized users. Such an integrated approach has the potential to enhance the process of data collection, hazard analysis, and risk information management. Our case study has shown that the system architecture is suitable for hazard-related emergency management. In addition, it might be useful for the implementation of technical landslide countermeasures as well as the development of mitigation measures.

Acknowledgments: The research has been funded by the project supported by National Science and Technology Ministry (2012BAK10B07-01) and Beijing Key Laboratory of Urban Spatial Information Engineering (2016102). We are grateful to China Institute of Water Resources and Hydropower Research and China Aero Geophysical Survey \& Remote Sensing Center for Land and Resources for providing data.

Author Contributions: Wei Hou and Xuejun LU had the original idea for the study and all co-authors conceived and designed the methodology. Pengda $\mathrm{Wu}, \mathrm{An}$ Xue and Like Li were responsible for the processing and analysis of the data. Wei Hou and Pengda Wu drafted the manuscript, which was revised by Xuejun Lu. All authors read and approved the final manuscript.

Conflicts of Interest: The authors declare no conflict of interest.

\section{References}

1. $\quad$ Lan, H.X.; Zhou, C.H.; Wang, L.J.; Zhang, H.Y.; Li, R.H. Landslide hazard spatial analysis and prediction using GIS in the Xiaojiang watershed, Yunnan, China. Eng. Geol. 2004, 76, 109-128. [CrossRef]

2. Tang, C.; Ma, G.; Chang, M.; Li, W.; Zhang, D.; Jia, T.; Zhou, Z. Landslides triggered by the 20 April 2013 Lushan earthquake, Sichuan Province, China. Eng. Geol. 2015, 187, 45-55. [CrossRef]

3. Hervás, J.; Barredo, J.I.; Rosin, P.L.; Pasuto, A.; Mantovani, F.; Silvano, S. Monitoring landslides from optical remotely sensed imagery: The case history of Tessina landslide, Italy. Geomorphology 2003, 54, 63-75. [CrossRef] 
4. Metternicht, G.; Hurni, L.; Gogu, R. Remote sensing of landslides: An analysis of the potential contribution to geo-spatial systems for hazard assessment in mountainous environments. Remote Sens. Environ. 2005, 98, 284-303. [CrossRef]

5. Biswajeet, P.; Saro, L. Utilization of Optical Remote Sensing Data and GIS Tools for Regional Landslide Hazard Analysis Using an Artificial Neural Network Model. Earth Sci. Front. 2007, 14, 143-151. [CrossRef]

6. McKillop, R.J.; Clague, J.J. Statistical, remote sensing-based approach for estimating the probability of catastrophic drainage from moraine-dammed lakes in southwestern British Columbia. Glob. Planet. Chang. 2007, 56, 153-171. [CrossRef]

7. Brien, D.L.; Reid, M.E. Assessing deep-seated landslide susceptibility using 3-D groundwater and slope-stability analyses, southwestern Seattle, Washington. Rev. Eng. Geol. 2008, 20, 83-101. [CrossRef]

8. Van Westen, C.J.; Lulie Getahun, F. Analyzing the evolution of the Tessina landslide using aerial photographs and digital elevation models. Geomorphology 2003, 54, 77-89. [CrossRef]

9. Kääb, A. Photogrammetry for early recognition of high mountain hazards: New techniques and applications. Phys. Chem. Earth Part B 2000, 25, 765-770. [CrossRef]

10. Schulz, W.H. Landslide susceptibility revealed by LIDAR imagery and historical records, Seattle, Washington. Eng. Geol. 2007, 89, 67-87. [CrossRef]

11. Niethammer, U.; James, M.R.; Rothmund, S.; Travelletti, J.; Joswig, M. UAV-based remote sensing of the Super-Sauze landslide: Evaluation and results. Eng. Geol. 2012, 128, 2-11. [CrossRef]

12. Carrara, A.; Cardinali, M.; Guzzetti, F.; Reichenbach, P. Gis Technology in Mapping Landslide Hazard. In Geographical Information Systems in Assessing Natural Hazards; Carrara, A., Guzzetti, F., Eds.; Advances in Natural and Technological Hazards Research; Springer: Dordrecht, The Netherlands, 1995; pp. 135-175.

13. Sarkar, S.; Kanungo, D.P. An Integrated Approach for Landslide Susceptibility Mapping Using Remote Sensing and GIS. Photogramm. Eng. Remote Sens. 2004, 70, 617-625. [CrossRef]

14. Assilzadeh, H.; Levy, J.K.; Wang, X. Landslide Catastrophes and Disaster Risk Reduction: A GIS Framework for Landslide Prevention and Management. Remote Sens. 2010, 2, 2259-2273. [CrossRef]

15. Thennavan, E.; Ganapathy, G.P.; Sekaran, S.S.C.; Rajawat, A.S. Use of GIS in assessing building vulnerability for landslide hazard in The Nilgiris, Western Ghats, India. Nat. Hazards 2016, 82, 1-20. [CrossRef]

16. Barredo, J.; Benavides, A.; Hervás, J.; van Westen, C.J. Comparing heuristic landslide hazard assessment techniques using GIS in the Tirajana basin, Gran Canaria Island, Spain. Int. J. Appl. Earth Obs. Geoinf. 2000, 2, 9-23. [CrossRef]

17. He, Y.P.; Xie, H.; Cui, P.; Wei, F.Q.; Zhong, D.L.; Gardner, J.S. GIS-based hazard mapping and zonation of debris flows in Xiaojiang Basin, southwestern China. Environ. Geol. 2003, 45, 286-293. [CrossRef]

18. Raghuvanshi, T.K.; Negassa, L.; Kala, P.M. GIS based Grid overlay method versus modeling approach-A comparative study for landslide hazard zonation (LHZ) in Meta Robi District of West Showa Zone in Ethiopia. Egypt. J. Remote Sens. Space Sci. 2015, 18, 235-250. [CrossRef]

19. Showalter, P.S. Remote sensing's use in disaster research: A review. Disaster Prev. Manag. 2001, 10, 21-29. [CrossRef]

20. Olsen, M.J.; Chen, Z.; Hutchinson, T.; Kuester, F. Optical techniques for multiscale damage assessment. Geomat. Nat. Hazards Risk 2013, 4, 49-70. [CrossRef]

21. Fekete, A.; Tzavella, K.; Armas, I.; Binner, J.; Garschagen, M.; Giupponi, C.; Mojtahed, V.; Pettita, M.; Schneiderbauer, S.; Serre, D. Critical Data Source; Tool or Even Infrastructure? Challenges of Geographic Information Systems and Remote Sensing for Disaster Risk Governance. ISPRS Int. J. Geo-Inf. 2015, 4, 1848-1869. [CrossRef]

22. Lichter, M.; Grinberger, A.Y.; Felsenstein, D. Simulating and Communicating Outcomes in Disaster Management Situations. ISPRS Int. J. Geo-Inf. 2015, 4, 1827-1847. [CrossRef]

23. Hagemeier-Klose, M.; Wagner, K. Evaluation of flood hazard maps in print and web mapping services as information tools in flood risk communication. Nat. Hazards Earth Syst. Sci. 2009, 9, 563-574. [CrossRef]

24. Huang, R. Mechanisms of large-scale landslides in China. Bull. Eng. Geol. Environ. 2011, 71, 161-170. [CrossRef]

25. Chen, G.; Li, X.; Chen, W.; Cheng, X.; Zhang, Y.; Liu, S. Extraction and application analysis of landslide influential factors based on LiDAR DEM: A case study in the Three Gorges area, China. Nat. Hazards 2014, 74, 509-526. [CrossRef] 
26. Birk, R.; Baldauf, B.; Ohlemacher, R.; Andreoli, L. Evaluating a system of systems approach for integrated global weather, climate, and hazard monitoring. In Proceedings of the AIAA SPACE 2008 Conference \& Exposition, San Diego, CA, USA, 9-11 September 2008; Volume 7085.

27. Verhoeven, G. Taking computer vision aloft-Archaeological three-dimensional reconstructions from aerial photographs with photoscan. Archaeol. Prospect. 2011, 18, 67-73. [CrossRef]

28. Kersten, T.P.; Lindstaedt, M. Image-Based Low-Cost Systems for Automatic 3D Recording and Modelling of Archaeological Finds and Objects. In Proceedings of the EuroMed 2012 4th International Conference on Progress in Cultural Heritage Preservation, Limassol, Cyprus, 29 October-3 November 2012; Ioannides, M., Fritsch, D., Leissner, J., Davies, R., Remondino, F., Caffo, R., Eds.; Springer: Berlin/Heidelberg, Germany, 2012; pp. 1-10.

29. Quantin, C.; Allemand, P.; Delacourt, C. Morphology and geometry of Valles Marineris landslides. Planet. Space Sci. 2004, 52, 1011-1022. [CrossRef]

30. Fell, R.; Corominas, J.; Bonnard, C.; Cascini, L.; Leroi, E.; Savage, W.Z. Guidelines for landslide susceptibility, hazard and risk zoning for land-use planning. Eng. Geol. 2008, 102, 99-111. [CrossRef]

31. Cascini, L. Applicability of landslide susceptibility and hazard zoning at different scales. Eng. Geol. 2008, 102, 164-177. [CrossRef]

32. Chacón, J.; Irigaray, C.; Fernández, T.; Hamdouni, R.E. Eng. Geol. maps: Landslides and geographical information systems. Bull. Eng. Geol. Environ. 2006, 65, 341-411. [CrossRef]

33. Carrara, A.; Cardinali, M.; Detti, R.; Guzzetti, F.; Pasqui, V.; Reichenbach, P. GIS techniques and statistical models in evaluating landslide hazard. Earth Surf. Process. Landf. 1991, 16, 427-445. [CrossRef]

34. Aleotti, P.; Chowdhury, R. Landslide hazard assessment: Summary review and new perspectives. Bull. Eng. Geol. Environ. 1999, 58, 21-44. [CrossRef]

35. Tate, E.; Burton, C.G.; Berry, M.; Emrich, C.T.; Cutter, S.L. Integrated Hazards Mapping Tool. Trans. GIS 2011, 15, 689-706. [CrossRef]

(C) 2017 by the authors. Licensee MDPI, Basel, Switzerland. This article is an open access article distributed under the terms and conditions of the Creative Commons Attribution (CC BY) license (http:/ / creativecommons.org/licenses/by/4.0/). 